\section{A) Check for updates}

Cite this: Food Funct., 2022, 13, 781

\title{
Supplementation with cyanidin and delphinidin mitigates high fat diet-induced endotoxemia and associated liver inflammation in mice $\dagger$
}

\author{
Eleonora Cremonini, (D) $\ddagger^{a, b}$ Dario E. Iglesias, (D) $\ddagger^{a, b}$ Karen E. Matsukuma, ${ }^{c}$ \\ Shelly N. Hester, ${ }^{d}$ Steven M. Wood, ${ }^{d}$ Mark Bartlett, ${ }^{d}$ Cesar G. Fraga (D) ${ }^{a, e, f}$ and \\ Patricia I. Oteiza (D) *a,b
}

\begin{abstract}
Consumption of high fat diets (HFD) and the associated metabolic endotoxemia can initiate liver inflammation and lipid deposition that with time can progress to non-alcoholic fatty liver disease (NAFLD). We previously observed that 14 weeks supplementation with the anthocyanidins cyanidin and delphinidin mitigated HFD-induced metabolic endotoxemia and liver insulin resistance, steatosis, inflammation and oxidative stress. This work investigated if a 4-week supplementation of mice with a cyanidin- and delphinidin-rich extract (CDRE) could mitigate or reverse HFD (60\% calories from lard fat)-induced liver steatosis and inflammation. After a first 4-weeks period on the HFD, mice showed increased endotoxemia and activation of liver proinflammatory signaling cascades. Supplementation with CDRE between weeks 4 and 8 did not mitigate liver steatosis or the altered lipid and glucose plasma levels. However, CDRE supplementation reverted HFD-induced metabolic endotoxemia, in parallel with the mitigation of the overexpression of hepatic TLR2 and TLR4, and of the activation of: (i) NF-kB, (ii) AP-1 and upstream mitogen-activated kinases $\mathrm{p} 38$ and ERK1/2, and (iii) HIF-1. Thus, even a short-term consumption of cyanidin and delphinidin could help mitigate the adverse consequences, i.e. metabolic endotoxemia and associated liver inflammation, triggered by the regular consumption of diets rich in fat.
\end{abstract}

Received 16th September 2021 Accepted 5th December 2021

DOI: $10.1039 / \mathrm{d} 1 \mathrm{fo} 03108 \mathrm{~b}$

rsc.li/food-function saccharide (LPS) concentration. ${ }^{1,2}$ This increase, defined as metabolic endotoxemia, can occur because of an increased passage of LPS from the intestinal lumen into the circulation. The underlying mechanisms can include: (i) LPS paracellular transport due to the permeabilization of the intestinal barrier, ${ }^{3,4}$ (ii) co-transport of LPS across enterocytes incorporated into nascent chylomicrons, ${ }^{5,6}$ and (iii) changes in intestinal microbiota leading to increased LPS production. ${ }^{7}$

Toll-like receptors (TLR) are involved in the pathogenesis of several chronic liver diseases. ${ }^{8}$ Molecularly, LPS binds to TLR4 leads to the activation of several signaling cascades, e.g. NF-kB and the mitogen activated kinases (MAPK), which promotes the transcription of chemokines and proinflammatory cytokines. The liver maintains low levels of TLR4 expression and manages LPS without significant inflammation. When exposed to high LPS concentrations, the liver upregulates TLR4 expression, which subsequent activation can trigger liver inflammation and fibrosis. ${ }^{9}$ If this condition becomes chronic in the liver, it can ultimately lead to tissue insulin resistance and NAFLD.

Anthocyanidins (AC) constitute a family of flavonoids bearing the basic flavonoid structure $\mathrm{C} 6-\mathrm{C} 3-\mathrm{C} 6$, with a positive charge in the heterocycle ring. Different patterns of 
hydroxylation characterize different AC, which mostly exist in nature as glycosylated derivatives (anthocyanins). Consumption of AC has been associated with amelioration of conditions bearing a significant proinflammatory component, including type 2 diabetes, ${ }^{10}$ cardiovascular disease ${ }^{11}$ and ulcerative colitis. ${ }^{12}$ However, in terms of mechanisms of action, different AC display different bioactivities. ${ }^{13,14}$ Thus, in their 3-O-glucosides forms, cyanidin and delphinidin are more efficient than other ACs like malvidin, petunidin and peonidin in attenuating tumor necrosis factor alpha ( $\mathrm{TNF} \alpha$ )-induced activation of the proinflammatory NF- $\kappa \mathrm{B}$ signaling pathway and preventing permeabilization of Caco- 2 cell monolayers, used as a model on intestinal epithelium. ${ }^{15}$ Similarly, cyanidin and delphinidin 3-O-glucosides were more efficient than malvidin and peonidin 3-O-glucosides at stimulating glucagon-like peptide 1 (GLP-1) release from intestinal enteroendocrine cells. $^{16}$

Dietary strategies oriented to decrease metabolic endotoxemia could help mitigate western style diets-associated liver inflammation and disease. In this regard, we previously observed that supplementation with a cyanidin and delphinidin rich extract (CDRE) prevented HFD-induced metabolic endotoxemia, and mitigated inflammation in mice fed a HFD for 14 weeks. ${ }^{17}$ Considering the above evidence, and the major role that endotoxemia plays in liver inflammation, and consequently in the development of liver diseases, this work investigated if a 4-week supplementation with the CDRE could reverse HFD-induced endotoxemia and the associated liver inflammation in mice. This period of AC supplementation prevented the increased endotoxemia caused by HFD consumption, in parallel with the mitigation of hepatic TLR4 and TLR2 overexpression and the activation of downstream proinflammatory cascades, i.e. NF- $\mathrm{BB}, \mathrm{HIF}-1$ and AP-1 and upstream MAPKs p38 and extracellular signal-regulated kinase (ERK) 1/2. Thus, increased cyanidin and delphinidin consumption could help mitigate the adverse consequences, i.e. metabolic endotoxemia and liver inflammation, associated to the regular consumption of diets with a high fat content.

\section{Materials and methods}

\section{Materials}

Cholesterol and triglyceride concentrations were determined using kits purchased from Wiener Lab Group (Rosario, Argentina). Glucose and alanine transaminase levels were measured using a kit purchased from Sigma-Aldrich Co (St Louis, MO). Concentrations of insulin were determined using a kit purchased from Crystal Chem Inc. (Downers Grove, IL). Antibodies for monocyte chemoattractant protein-1 (MCP-1) (\#2029), TNF $\alpha$ (\#11948), phospho (Ser176/180)-IKK $\alpha / \beta$ (\#2697), IKK $\alpha$ (\#2682), phospho (Ser536)-p65 (\#3033), p65 (\#8242), TLR2 (\#13744), phospho (Thr180/Tyr182)-p38 (\#9211), phospho (Thr202/Tyr204)-ERK (\#4370), ERK (\#9102), and $\beta$-actin (\#12620) were obtained from Cell Signaling Technology (Danvers, MA). Oligonucleotides for NF- $\mathrm{BB}$ (sc-2505) and AP-1 (sc-2501), and antibodies for Col1A1 (collagen type I alpha 1 chain) (sc-293182), fibronectin (sc-271098), TLR4 (sc-293072), nitric oxide synthase 2 (iNOS) (sc-649), p38 $\alpha / \beta$ (sc-7149) and HSC-70 (sc-1059) were from Santa Cruz Biotechnology (Santa Cruz, CA). Antibodies for 4-hydroxynonenal (4-HNE) (ab46545), NOX1 (ab55831), NOX4 (ab216654) and gp91 ${ }^{\text {phox }}(\mathrm{ab} 129068)$ and the kit to measure free fatty acids concentrations were purchased from Abcam, Inc. (Cambridge, MA). Hematoxylin and eosin solutions were from Thermo Fisher Scientific Inc. (Piscataway, NJ). Plasma endotoxin levels were measured using a kit from Abbexa LLC (Houston, TX). T4 polynucleotide kinase and reagents for EMSA assays were from Promega (Madison, WI). $\left[\gamma^{-}{ }^{32} \mathrm{P}\right]$ ATP was from PerkinElmer (Waltham, MA). PVDF membranes and Clarity Western ECL Substrates were obtained from Bio-Rad (Hercules, CA). All other chemicals were purchased from Sigma-Aldrich Co (St Louis, MO). The CDRE was provided by NSE Products, Inc. (Provo, UT).

\section{Determination of AC blend composition}

Polyphenols present in the CDRE were determined by HPLC (a service generously provided by Dr Mary Ann Lila's lab, North Carolina State University). The CDRE composition is shown in ESI Table $1 . \dagger$

\section{Animals and animal care}

All procedures were in agreement with standards for care of laboratory animals as outlined in the NIH Guide for the Care and Use of Laboratory Animals; experimental protocols were approved before implementation by the University of California, Davis Animal Use and Care Administrative Advisory Committee. Procedures were administered under the auspices of the Animal Resource Services of the University of California, Davis.

Mice were purchased from The Jackson Laboratories (Sacramento, CA). Sixty mice (5-weeks old male C57BL/6J, 20-25 g) were acclimated for one week to the control diet and subsequently fed for 4 weeks with: (i) a diet containing approximately $10 \%$ total calories from fat (control, C group); or (ii) a diet containing approximately $60 \%$ total calories from fat (lard) (HF group). After 4 weeks on these diets, 10 mice per group were euthanized, and the 20 remaining in each group were divided in two subgroups (10 mice per subgroup) that either continued on the control and HFD, or were supplemented with CDRE to receive $50 \mathrm{mg}$ of cyadinin $(28.9 \mathrm{mg})+$ delphinidin (21.1 $\mathrm{mg}$ ) per $\mathrm{kg}$ body weight (control diet supplemented with CDRE, CA group; HFD supplemented with CDRE, HFA group) for 4 weeks (Fig. 1A). The amount of CDRE was calculated to represent an achievable human consumption/supplementation and adjust it to mice using ReaganShaw et al. ${ }^{18}$ scaling criteria. Based on this calculation and for a $70 \mathrm{~kg}$ person, the human equivalent dose of $50 \mathrm{mg}$ per $\mathrm{kg}$ body weight of cyanidin and delphinidin corresponds, for example, to $50 \mathrm{~g}$ of fresh black currants. This is calculated according with reported AC content in foods. ${ }^{19}$

Body weight and food intake were measured weekly throughout the study. After 2 weeks on the diets, a blood 


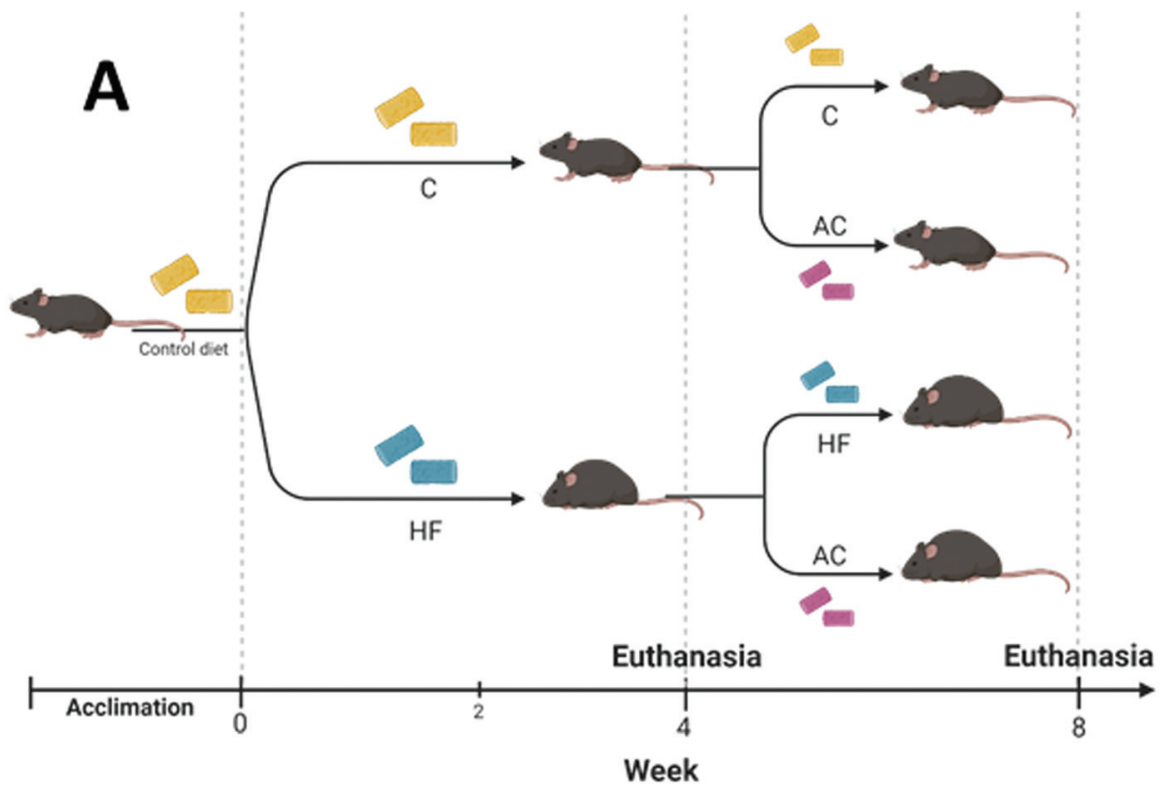

B
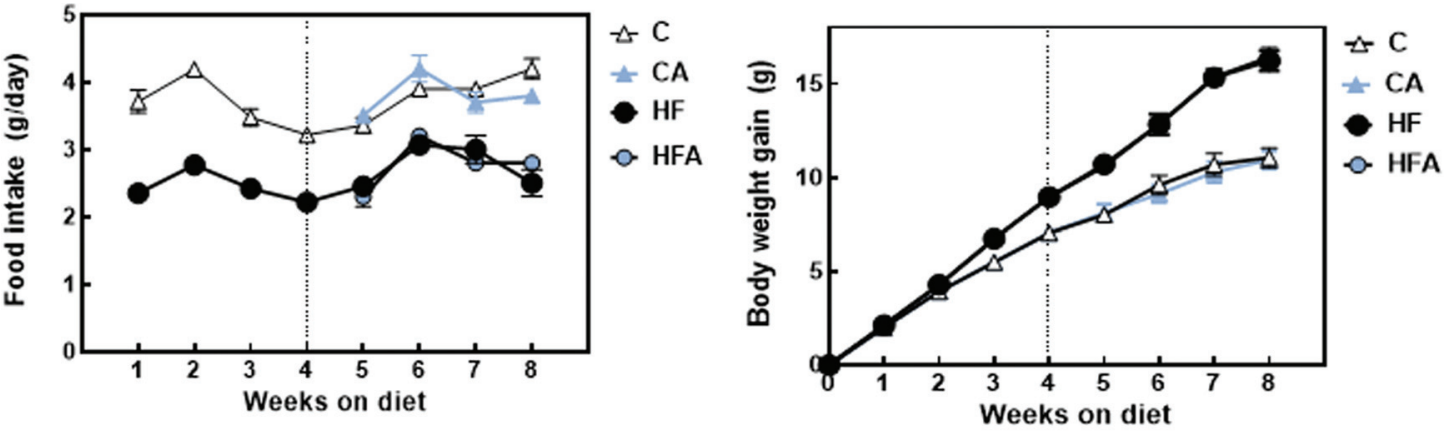

D

E
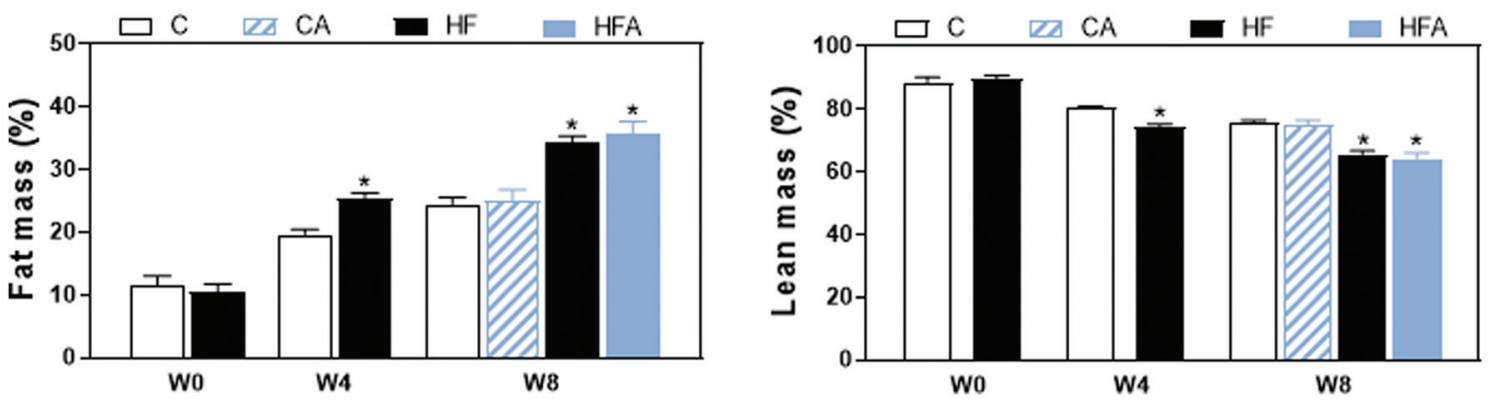

Fig. 1 Effects of the supplementation with a cyanidin- and delphinidin-rich extract on metabolic parameters in mice fed control and high fat diets. A - Experimental design, B - food intake and C - body weight gain. D and E Body composition after 0, 4 or 8 weeks on the dietary treatments. Mice were fed a control diet (empty triangles, white bars) (C) or a HFD (black circles, black bars) (HF) for 8 weeks, or the control diet for 4 weeks and the control diet supplemented with CDRE (50 mg of cyanidin + delphinidin) per kg body weight for the subsequent 4 weeks (full blue triangles, dashed blue bars) (CA); or the HFD for 4 weeks and the HFD supplemented with CDRE (50 mg of cyanidin + delphinidin) per kg body weight for the subsequent 4 weeks (full blue circles, blue bars) (HFA). Results are shown as means \pm SE and are the average of 9-10 mice per group. Values having different symbols are significantly different $(P<0.05$, one-way ANOVA). B - Differences in body weight gain values between the control- and HFDfed groups were significant after 3 to 8 weeks on the diets $(P<0.05$, repeated measures ANOVA). 
sample $(20 \mu \mathrm{l})$ was collected from the submandibular vein. Body composition was measured at 4 and 8 weeks on the diets using EchoMRI, EchoMRI LCC (Houston, TX) the day before the mice were euthanized.

After 4 or 8 weeks on the dietary treatments, mice were euthanized by cervical dislocation, blood was collected from the sub-mandibular vein into EDTA tubes, and plasma was obtained after centrifugation at $3000 \mathrm{~g}$ for $15 \mathrm{~min}$ at room temperature. Different adipose tissue pads and livers were collected and weighed. Tissues were either processed for histology or flash frozen in liquid $\mathrm{N}_{2}$ and then stored at $-80{ }^{\circ} \mathrm{C}$ for further analysis.

\section{Determination of liver lipids content}

Lipid triglycerides, cholesterol and free fatty acids content were measured using different methods. Analysis of liver triglyceride content was performed after extraction and saponification as previously described by Weber et al. with minor modifications. ${ }^{20}$ Briefly, a $100 \mu \mathrm{l}$ aliquot of $10 \%(\mathrm{w} / \mathrm{v})$ liver homogenate was mixed with $300 \mu \mathrm{l}$ of a $\mathrm{KOH}(30 \% \mathrm{w} / \mathrm{v})$ : ethanol $(1: 2$, $\mathrm{v}: \mathrm{v})$ solution and evaporated overnight at $55^{\circ} \mathrm{C}$. The following day, $1 \mathrm{ml}$ of $50 \%(\mathrm{v} / \mathrm{v})$ ethanol was added and samples centrifuged for $5 \mathrm{~min}$ at $10000 \mathrm{~g}$ at room temperature. Of the resulting supernatant, $200 \mu \mathrm{l}$ were added with $215 \mu \mathrm{l}$ of $1 \mathrm{M} \mathrm{MgCl}_{2}$ and placed on ice for $10 \mathrm{~min}$. After centrifugation at $10000 \mathrm{~g}$ for $5 \mathrm{~min}$ at room temperature, $10 \mu \mathrm{l}$ of the supernatant were analyzed for triglyceride content using the enzymatic triglyceride kit TG Color GPO/PAP AA (Wiener Lab, Rosario, Argentina). Liver cholesterol content was determined using the Bligh and Dyer method ${ }^{21}$ with some modifications. Briefly, a $300 \mu \mathrm{l}$ aliquot of $10 \%(\mathrm{w} / \mathrm{v})$ liver homogenate was mixed with $900 \mu \mathrm{l}$ of a chloroform : methanol $(2: 1, \mathrm{v}: \mathrm{v})$ solution. After centrifugation at $3000 \mathrm{~g}$ for $10 \mathrm{~min}$, the supernatant was discarded and the lower phase was collected and evaporated for $1 \mathrm{~h}$ and 30 min using an Eppendorf Vacufuge (Eppendorf, Hamburg, Germany). After evaporation, the pellet was resuspended with $50 \mu \mathrm{l}$ of methanol plus $0.05 \%$ (v/v) Tween-20 solution and sonicated. $10 \mu \mathrm{l}$ of the lipid suspension were analyzed for cholesterol content using the enzymatic total cholesterol kit Cholestat (Wiener Lab, Rosario, Argentina). Free fatty acid content was determined following the manufacturers' instructions (Free Fatty Acid quantification assay kit, Abcam Inc., Cambridge, MA). Briefly, $10 \mathrm{mg}$ of liver were homogenized in $200 \mu \mathrm{l}$ of $1 \%(\mathrm{v} / \mathrm{v})$ Triton X-100 in chloroform and incubated on ice for $20 \mathrm{~min}$. The extract was centrifuged at $14000 \mathrm{~g}$ for $5 \mathrm{~min}$ at room temperature. The organic phase collected was first air dried at $50{ }^{\circ} \mathrm{C}$ and then vacuum dried for $30 \mathrm{~min}$. Dried lipids were resuspended in $200 \mu \mathrm{l}$ of fatty acid assay buffer provided by the kit, and vortexed extensively for $5 \mathrm{~min}$. Free fatty acid concentration was determined by fluorometric assay following the manufacturers' instructions.

\section{Metabolic measurements}

Plasma total cholesterol, triglycerides, free fatty acids, alanine aminotransferase (ALT), glucose and insulin concentrations were determined following manufacturer's guidelines. Plasma endotoxin levels were determined using a kit from Abbexa LCC (Houston, TX) following the manufacturer's protocols.

\section{Histological analyses}

Liver samples were fixed overnight in $4 \%(\mathrm{w} / \mathrm{v})$ neutralized paraformaldehyde solution. Samples were subsequently washed twice in phosphate buffered saline solution, dehydrated, and then embedded in paraffin for histological analysis. Sections (5 $\mu \mathrm{m}$ thickness) were obtained from paraffin blocks and placed on glass slides. Hematoxylin and eosin (H\&E) staining was performed following standard procedures. Sections were examined using an Olympus BX46 microscope, with 10× ocular lenses (field number 22) (Olympus America Inc., Center Valley, PA). The pathologist was blinded to the identity of all samples. After review, the specimens fell into discrete histologic categories that were designated as "hepatic injury patterns". These patterns were: (i) normal, Zone 1 Pallor and Zone 3 Pallor, defined as no significant hepatocytes change; up to minimal macrovesicular steatosis; (ii) microvesicular, defined as enlarged hepatocytes with minute intracytoplasmic fat droplets; and (iii) hypertrophy/balloon, defined as slightly enlarged to notably enlarged hepatocytes with clear cytoplasm. The images were numerically scored according to Kleiner et al. ${ }^{22}$

\section{Western blot analysis}

Livers were homogenized as previously described ${ }^{23}$ using a BeadMill24 (Thermo Fisher Scientific Inc., Piscataway, NJ). Aliquots of total homogenates containing $30 \mu \mathrm{g}$ protein were denatured with Laemmli buffer, separated by reducing 8-15\% polyacrylamide gel electrophoresis, and electroblotted to PVDF membranes. Membranes were blocked for $1 \mathrm{~h}$ in $5 \%(\mathrm{w} / \mathrm{v})$ bovine serum albumin or non-fat dry milk, and subsequently incubated in the presence of the corresponding primary antibodies (1:1000 dilution) overnight at $4{ }^{\circ} \mathrm{C}$. After incubation for $90 \mathrm{~min}$ at room temperature in the presence of the corresponding secondary antibodies (HRP conjugated) (1:10 000 dilution), the conjugates were visualized using enhanced chemiluminescence. Images were captured using a Bio-Rad ChemiDoc Imager, and bands quantified using Image Lab Software (Bio-Rad, Hercules, CA).

\section{Electrophoretic mobility shift assay (EMSA)}

NF-кB- and AP-1-DNA binding were assessed in liver nuclear fractions isolated as previously described. ${ }^{24,25}$ The EMSA was performed by end labeling the oligonucleotide containing the consensus sequences for NF- $\mathrm{BB}$ with $\left[\gamma^{-32} \mathrm{P}\right]$ ATP. The oligonucleotide was end-labeled using $\mathrm{T} 4$ polynucleotide kinase and purified using Chroma Spin-10 columns. Samples were incubated with the labelled oligonucleotide (20000-30000 cpm) for $20 \mathrm{~min}$ at room temperature in $1 \times$ binding buffer $[5 \times$ binding buffer: $50 \mathrm{mM}$ Tris-HCl buffer, $\mathrm{pH} 7.5$, containing $20 \%$ (v/v) glycerol, $5 \mathrm{mM} \mathrm{MgCl}_{2}$, $2.5 \mathrm{mM}$ EDTA, $2.5 \mathrm{mM}$ DTT, $250 \mathrm{mM} \mathrm{NaCl}$, and $0.25 \mathrm{mg} \mathrm{ml}^{-1}$ poly $\left.(\mathrm{dI}-\mathrm{dC})\right]$. The products were separated by electrophoresis in a $6 \%(\mathrm{w} / \mathrm{v})$ non-denaturing polyacrylamide gel using 0.5 TBE (45 mM Tris/borate, 
1 mM EDTA, pH 8.3) as the running buffer. The gels were dried and the radioactivity quantified in a Phosphoimager 840 (Amersham Pharmacia Biotech. Inc., Piscataway, NJ).

\section{Statistical analysis}

Data were analyzed by one-way analysis of variance (ANOVA) using Statview 5.0 (SAS Institute Inc., Cary, NC). Fisher least significance difference test was used to examine differences between group means. A repeated measure ANOVA with TukeyKramer multiple comparison test was used to analyze changes in body weight and food intake. A $P$ value $<0.05$ was considered statistically significant. Data are shown as means \pm SE.

\section{Results}

\section{Effects of the HFD and supplementation with cyanidin and delphinidin on body weight gain and composition}

Average daily food intake during the last 4 weeks of the study was significantly lower in mice receiving the HFD compared to those receiving control diets throughout the study (Fig. 1B). Within the same period, average daily caloric intake was similar for both groups (Table 1). After 8 weeks on the corresponding diets, consumption of the HFD caused a $17 \%$ increase in body weight (Table 1). Body weight gain in the HF group started being significantly higher compared to the control group after 3 weeks on the HFD (Fig. 1C). CDRE supplementation during the last 4 weeks did not affect food intake and body weight gain in both control diet- and HFD-fed mice (Fig. 1B and C).

Mice fed the HFD had $30 \%$ and $40 \%$ higher body fat mass, and $7 \%$ and $13 \%$ lower body lean mass at weeks 4 and 8 , respectively. CDRE supplementation had no effect on body fat or lean mass (Fig. 1D and E). Accordingly, at week 8 the weight of the subcutaneous, epididymal, visceral, and retroperitoneal fat pads was $48-92 \%$ higher in the $\mathrm{HF}$ compared to the $\mathrm{C}$ group (Table 2). CDRE supplementation did not affect any of the above parameters.

\section{Effects of the HFD and AC supplementation on metabolic parameters}

After 8 weeks on the diets, plasma total cholesterol and triglyceride concentrations were 15 and $25 \%$ higher in the HF than in the $\mathrm{C}$ group (Table 1). CDRE supplementation did not change total cholesterol increase. Plasma triglyceride levels in the HFA were not significantly different compared to the other three groups. Plasma fatty acid levels were not affected by the dietary treatments.

Glucose and insulin plasma levels were 24 and 67\% higher in the HF than in the $\mathrm{C}$ group; the HOMA-IR was $78 \%$ higher in HF mice, indicating a condition of insulin resistance. CDRE supplementation did not change these parameters.

Table 1 Body weight, food and caloric intake and metabolic parameters. Mice fed a control diet (C) or a HFD (HF) for 8 weeks, or the control diet for 4 weeks and the control diet supplemented with $50 \mathrm{mg} \mathrm{AC}$ per kg body weight for subsequent 4 weeks (CA) or the HFD for 4 weeks and the HFD supplemented with $50 \mathrm{mg} \mathrm{AC}$ per kg body weight for subsequent 4 weeks (HFA). Food intake and caloric intake correspond to the last 4 weeks on the diets. Total cholesterol, triglycerides, free fatty acid, glucose, insulin, and ALT were measured in plasma. Values are shown as means \pm SE (10 animals per group). Values having different superscripts are significantly different $(P<0.05$, one-way ANOVA)

\begin{tabular}{|c|c|c|c|c|}
\hline Parameter & $\mathrm{C}$ & $\mathrm{CA}$ & $\mathrm{HF}$ & HFA \\
\hline Food intake $\left(\mathrm{g}\right.$ day $\left.^{-1}\right)$ & $4.2 \pm 0.2^{\mathrm{a}}$ & $3.8 \pm 0.1^{\mathrm{a}}$ & $2.5 \pm 0.2^{\mathrm{b}}$ & $2.8 \pm 0.2^{\mathrm{b}}$ \\
\hline Caloric intake $\left(\mathrm{kcal} \mathrm{g}^{-1}\right.$ day $\left.^{-1}\right)$ & $13.8 \pm 0.3^{\mathrm{a}}$ & $13.9 \pm 0.1^{\mathrm{a}}$ & $13.7 \pm 0.3^{\mathrm{a}}$ & $13.2 \pm 0.3^{\mathrm{a}}$ \\
\hline $\mathrm{BW}(\mathrm{g})$ & $32.8 \pm 0.7^{\mathrm{a}}$ & $32.6 \pm 0.8^{\mathrm{a}}$ & $38.4 \pm 0.8^{\mathrm{b}}$ & $38.0 \pm 0.8^{\mathrm{b}}$ \\
\hline Liver weight (g) & $1.38 \pm 0.04^{\mathrm{a}}$ & $1.40 \pm 0.05^{\mathrm{a}}$ & $1.24 \pm 0.04^{\mathrm{b}}$ & $1.26 \pm 0.05^{\mathrm{b}}$ \\
\hline Triglycerides (mg dl $\left.{ }^{-1}\right)$ & $84.1 \pm 2.4^{\mathrm{a}}$ & $86.4 \pm 3.0^{\mathrm{a}}$ & $105.5 \pm 5.9^{b}$ & $100.2 \pm 5.9^{\mathrm{a}, \mathrm{b}}$ \\
\hline Total cholesterol $\left(\mathrm{mg} \mathrm{\textrm {dl } ^ { - 1 }}\right.$ ) & $189 \pm 8^{\mathrm{a}}$ & $193 \pm 4^{\mathrm{a}}$ & $218 \pm 11^{\mathrm{b}}$ & $226 \pm 8^{b}$ \\
\hline Free fatty acids $(\mu \mathrm{M})$ & $344 \pm 47^{\mathrm{a}}$ & $346 \pm 50^{\mathrm{a}}$ & $326 \pm 36^{\mathrm{a}}$ & $379 \pm 37^{\mathrm{a}}$ \\
\hline Glucose $\left(\mathrm{mg} \mathrm{dl}^{-1}\right)$ & $274 \pm 19^{\mathrm{a}}$ & $265 \pm 10^{\mathrm{a}}$ & $341 \pm 14^{\mathrm{b}}$ & $336 \pm 19^{b}$ \\
\hline Insulin $\left(\mathrm{ng} \mathrm{ml}^{-1}\right)$ & $1.2 \pm 0.2^{\mathrm{a}}$ & $1.2 \pm 0.2^{\mathrm{a}}$ & $2.0 \pm 0.2^{b}$ & $2.0 \pm 0.2^{\mathrm{b}}$ \\
\hline HOMA-IR & $0.9 \pm 0.2^{\mathrm{a}}$ & $0.8 \pm 0.1^{\mathrm{a}}$ & $1.6 \pm 0.2^{\mathrm{a}}$ & $1.7 \pm 0.2^{\mathrm{a}}$ \\
\hline $\mathrm{ALT}\left(\mathrm{mU} \mathrm{ml}^{-1}\right)$ & $33.8 \pm 1.7^{\mathrm{a}}$ & $30.7 \pm 2.2^{\mathrm{a}}$ & $33.5 \pm 1.3^{\mathrm{a}}$ & $31.9 \pm 3.2^{\mathrm{a}}$ \\
\hline
\end{tabular}

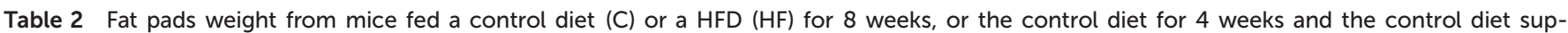

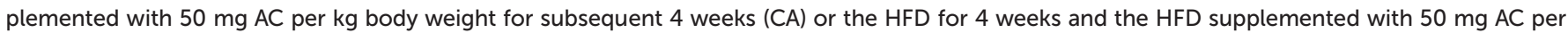

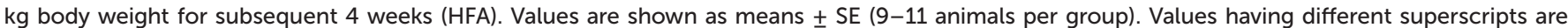
significantly different $(P<0.05$, one-way ANOVA)

\begin{tabular}{|c|c|c|c|c|}
\hline Tissue (g) & $\mathrm{C}$ & $\mathrm{CA}$ & $\mathrm{HF}$ & HFA \\
\hline Subcutaneous fat & $1.72 \pm 0.10^{\mathrm{a}}$ & $1.80 \pm 0.13^{\mathrm{a}}$ & $3.30 \pm 0.22^{\mathrm{b}}$ & $3.40 \pm 0.24^{\mathrm{b}}$ \\
\hline Epididymal fat & $1.28 \pm 0.06^{\mathrm{a}}$ & $1.31 \pm 0.07^{\mathrm{a}}$ & $2.31 \pm 0.12^{\mathrm{b}}$ & $2.25 \pm 0.13^{b}$ \\
\hline Visceral fat & $0.46 \pm 0.03^{\mathrm{a}}$ & $0.47 \pm 0.03^{\mathrm{a}}$ & $0.68 \pm 0.07^{\mathrm{b}}$ & $0.75 \pm 0.07^{\mathrm{b}}$ \\
\hline Retroperitoneal fat & $0.45 \pm 0.25^{\mathrm{a}}$ & $0.55 \pm 0.06^{\mathrm{a}}$ & $0.83 \pm 0.06^{b}$ & $0.82 \pm 0.05^{\mathrm{b}}$ \\
\hline Brown fat & $0.17 \pm 0.01^{\mathrm{a}}$ & $0.17 \pm 0.01^{\mathrm{a}}$ & $0.18 \pm 0.01^{\mathrm{a}}$ & $0.20 \pm 0.02^{\mathrm{a}}$ \\
\hline
\end{tabular}


Effects of the HFD and supplementation with cyanidin and delphinidin on steatosis

We next investigated the effects of the HFD and CDRE supplementation on the development of steatosis and liver damage. Liver weight was $10 \%$ lower in the HF and HFA groups compared to controls. Plasma alanine aminotransferase concentration, measured as a parameter of liver damage, was similar among groups (Table 1). After 8 weeks on the diets, liver triglycerides content was $15 \%$ higher in the HF compared to the $\mathrm{C}$ group. Supplementation with CDRE did not prevent liver TG accumulation. After 8 weeks on the HFD, liver cholesterol and free fatty acid content were similar among all groups (Fig. 2B). Protein levels of two markers of liver fibrosis, i.e. Col1A1 and fibronectin, were similar among all groups (Fig. 2C).

Hepatocellular injury triggered by agents such as fat and toxins could cause hepatic enzyme induction, leading to microvesicular steatosis and hypertrophy/ballooning. These clinical features are critical in the development and progression of NAFLD. ${ }^{26,27}$ After liver staining with hematoxylin/ eosin, alterations in hepatocytes injury pattern were evaluated, scoring: (i) microvesicular steatosis, a distinct form of steatosis which is less common in human NAFLD but features more prominently in rodent NAFLD; and (ii) hepatocyte hypertrophy/balloon, characterized by enlarged hepatocytes with clear cytoplasm. The proportion of hepatocytes containing microvesicular steatosis, and hepatocyte hypertrophy was significantly higher in the high fat compared to the control groups (Fig. 2D and E), suggesting an early stage of steatosis and liver injury. CDRE supplementation had no effects on these parameters.

\section{Effects of the HFD and supplementation with cyanidin and} delphinidin on endotoxemia and liver TLR upregulation

Consumption of a HFD can lead to endotoxemia, which can initiate liver inflammation and promote disease, e.g. NAFLD. Thus, we next evaluated plasma LPS levels. Compared to controls, a trend $(41 \%, P=0.078)$ for higher plasma endotoxin concentration was observed after 4 weeks on the HFD (Fig. 3A). At 8 weeks on the HFD, plasma endotoxin concentration was significantly higher $(44 \%, P<0.04)$ in the HF group than in controls (Fig. 3A and B). CDRE supplementation cancelled HFD-associated endotoxemia (Fig. 3B).

Upregulation of TLR receptors is frequently found associated to endotoxemia. Both TLR4 and TLR2 liver protein levels were not significantly affected after 4 weeks on the HFD (ESI Fig. $1 \dagger$ ); but after 8 weeks on this diet they were 45 and $42 \%$ higher, respectively, in $\mathrm{HF}$ mice compared to the $\mathrm{C}$ group (Fig. 3C). CDRE supplementation for 4 weeks prevented liver TLR2 and TLR4 upregulation.

Effects of the HFD and supplementation with cyanidin and delphinidin on signaling cascades downstream the TLRs: NF-кB

Activation of the TLR4 and TLR2 receptors can activate proinflammatory signaling cascades, e.g. NF- $\mathrm{B}$, MAPKs and AP-1. We evaluated NF- $\mathrm{BB}$ activation by measuring the phosphorylation of both, IKK and p65 by western blot, and NF-кB-DNA binding in nuclear fractions by EMSA. After 4 weeks on the HFD, no changes were observed in the phosphorylation of p65 at Ser536 (ESI Fig. $1 \dagger$ ). After 8 weeks on the diets, phosphorylation of $\mathrm{IKK} \alpha / \beta$ at Ser176/180 and of p65 were 27 and $38 \%$ higher in the HF than in the C group, respectively (Fig. 4B); CDRE supplementation of HFD-fed mice prevented both increases. Accordingly, NF-кB-DNA binding was significantly higher in nuclear fractions from HF mice compared to $\mathrm{C}$ and HFA mice (Fig. 4A). NF- $\kappa$ B regulates the transcription of genes involved in the proinflammatory response. Among them, we next evaluated the liver protein levels of the chemokine MCP-1, the cytokine TNF $\alpha$ and of inducible nitric oxide synthase (iNOS) (Fig. 4C). MCP-1 and TNF $\alpha$ levels were already elevated in the $\mathrm{HF}$ group compared to the $\mathrm{C}$ group after 4 weeks on the HFD ( $43 \%$ and 1.25-fold higher, respectively) (ESI Table $1 \dagger$ ). After 8 weeks, MCP-1 and TNF $\alpha$ protein levels were 3- and 2.3-fold higher in the HF group compared to the $\mathrm{C}$ group. While CDRE supplementation mitigated HFD-mediated MCP-1 increase, it did not affect TNF $\alpha$ upregulation. At week 8, iNOS levels were higher in the HF compared to the $\mathrm{C}$ and CA groups, while they were not significantly different between the HFA and the HF and CA groups.

Effects of the HFD and supplementation with cyanidin and delphinidin on signaling cascades downstream the TLRs: AP-1

AP-1 is activated by the family of MAPKs that include p38, ERK1/2 and JNK. After 8 weeks on the HFD, AP-1 activation, measured as AP-1-DNA binding by EMSA, was 50\% higher in the HF group compared to all other groups (Fig. 5A). A positive correlation was observed between NF-кB-and AP-1-DNA binding activity $(P=0.001, r$ : 0.63$)$. From the AP-1 upstream kinases, we observed that after 4 weeks on the HFD, only ERK1/2 phosphorylation at Thr202/Tyr204 was significantly higher than in control diet-fed mice (ESI Fig. 1†). After 8 weeks, liver phosphorylation levels of p38 at Thr180/Tyr182 and of ERK1/2 at Thr202/Tyr204 were 92 and 34\% higher, respectively, in the HF group compared to the control group (Fig. 5B). CDRE supplementation for 4 weeks prevented HFDinduced increased p38 phosphorylation, and restored ERK1/2 phosphorylation levels to control values (Fig. 5B). JNK phosphorylation at Thr183/Tyr185 was not affected by HFD consumption (data not shown).

Transcription factor HIF-1 is also involved in LPS-mediated inflammatory responses. ${ }^{28}$ HIF-1-DNA binding was $40 \%$ higher in HFD-fed mice compared to the control and HFA groups (Fig. 5C). A positive correlation was observed between the DNA-binding activity for HIF-1 and that of NF-kB $(P=$ $0.001, r: 0.56)$ and AP-1-DNA $(P=0.0004, r: 0.63)$.

\section{Effects of the HFD and supplementation with cyanidin and delphinidin on parameters of oxidative stress}

Oxidative stress is a major contributor to the development of NAFLD. Thus, we next investigated the expression of NADPH NOX1, NOX2 (gp91 ${ }^{\text {phox }}$ ) and NOX4. Protein levels of NOX1 and NOX4 were elevated (69 and 53\%, respectively) in the HF and HFA groups compared to controls, while no changes were 


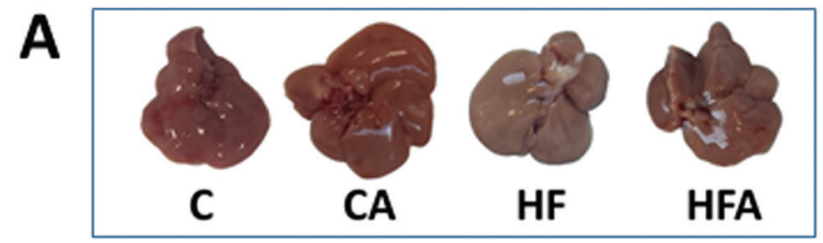

B
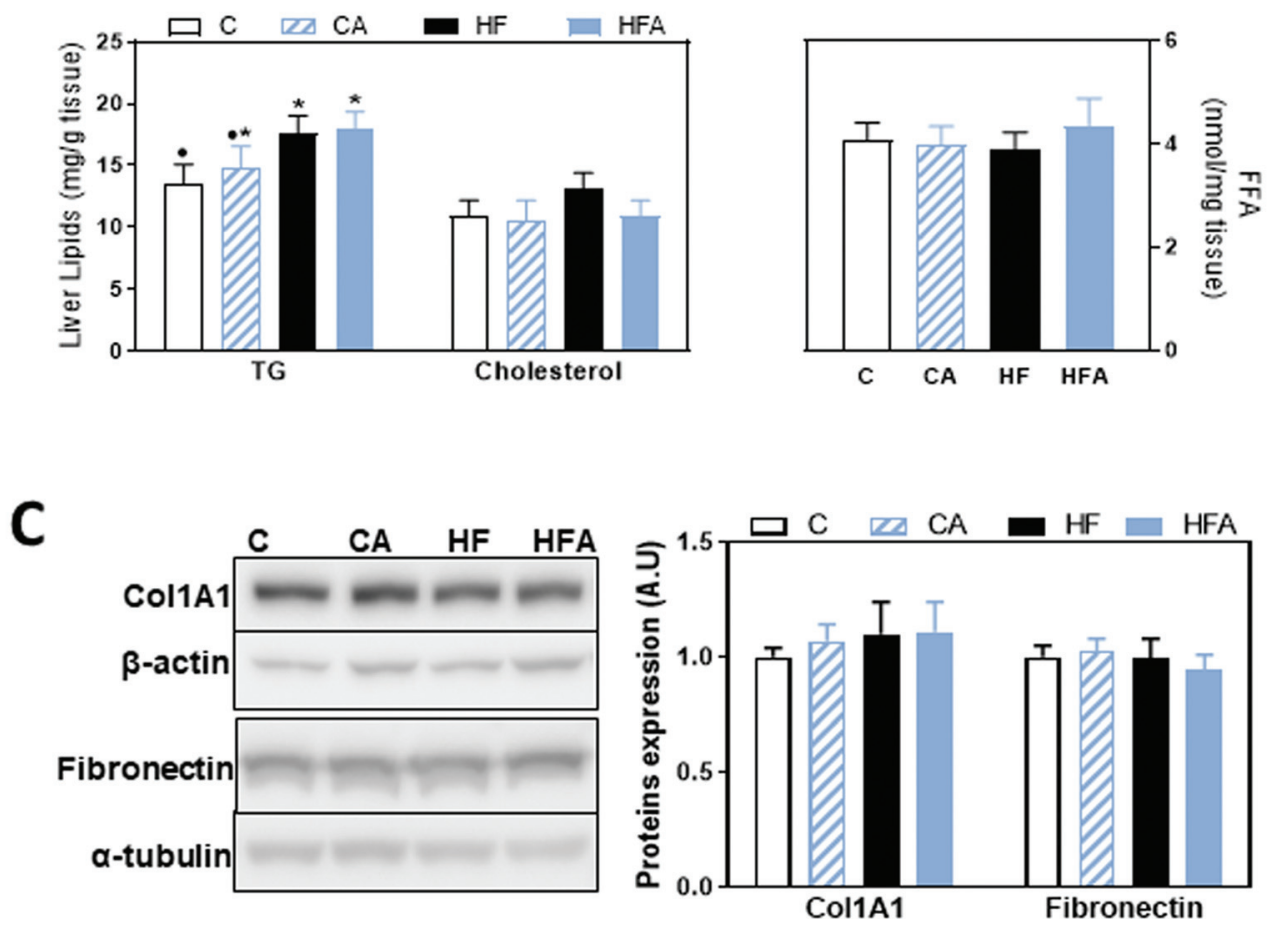

D

C

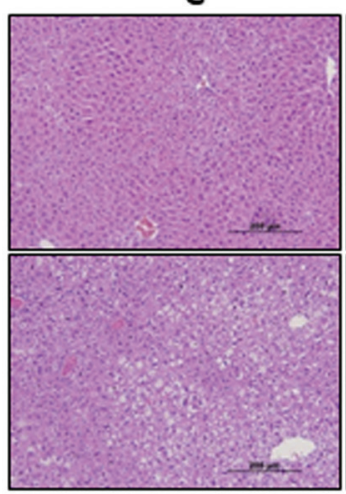

HF
CA

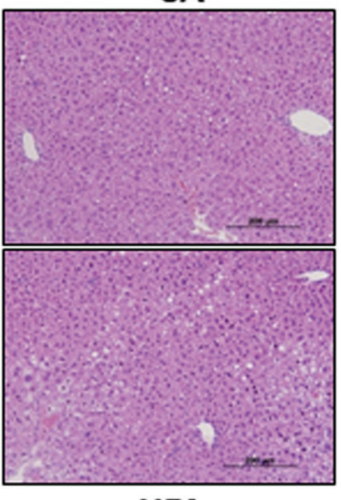

HFA
$\mathbf{E}$

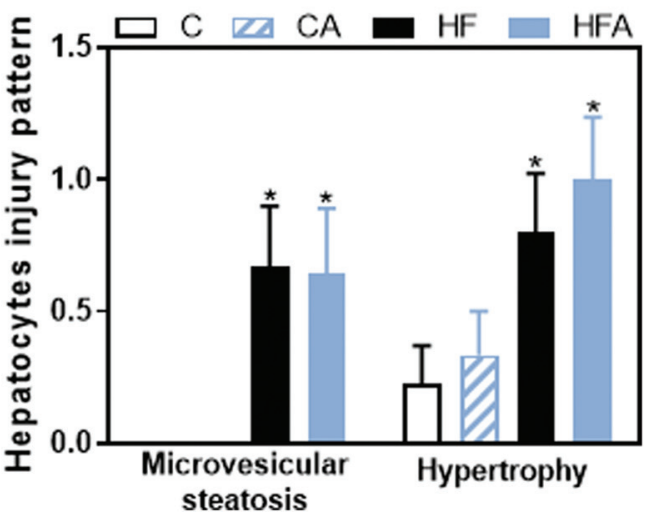

Fig. 2 Effects of the supplementation with a cyanidin- and delphinidin-rich extract on liver steatosis in mice fed a HFD. Mice were fed the different diets as described in methods. After 8 weeks on the corresponding treatments: A - liver images, B - liver triglycerides (TG), cholesterol and free fatty acid (FFA) content, C - proteins involved in fibrosis, i.e. Col1A1 and fibronectin, were evaluated by western blot and values normalized to $\beta$-actin or $\alpha$-tubulin levels, respectively (loading controls). Results for CA, HF and HFA were referred to control group values (C). D - Images of liver hematoxylin/eosin tissue staining, E - microvesicular steatosis and hypertrophy were evaluated as described in methods. All results are shown as mean \pm SE of 9 mice per group. Values having different superscripts are significantly different $(P<0.05$, one-way ANOVA test). 
A
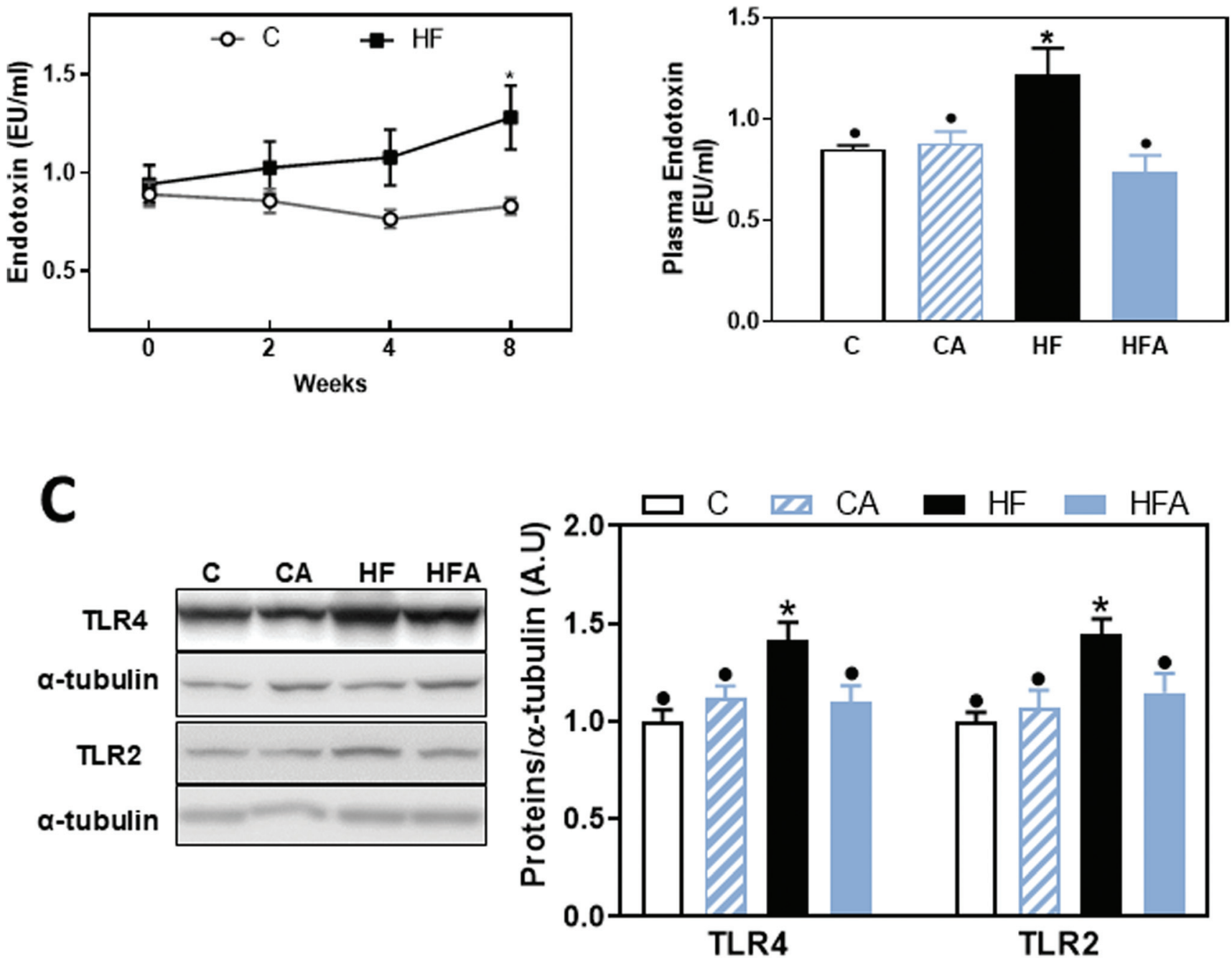

Fig. 3 Effects of the supplementation with cyanidin and delphinidin on endotoxemia and liver TLR expression in mice fed HFD. Mice were fed the different diets as described in methods. At weeks $0,2,4$ and/or 8 on the corresponding diets the following parameters were measured: $A$ and $B-$ Plasma endotoxin concentration. A-Kinetics of plasma endotoxin concentration in mice from the $\mathrm{C}$ and HF groups, B - plasma endotoxin concentration, and C - liver TLR2 and TLR4 protein levels after 8 weeks on the corresponding treatments. For western blots, bands were quantified, values referred to $\alpha$-tubulin levels (loading control) and results for CA, HF and HFA were referred to control group values (C). Results are shown as mean \pm SE of 9-10 mice per group. A - *Significantly different from $C$ at the corresponding time point; $B$ and $C$ - values having different symbols are significantly different $(P<0.05$, one-way ANOVA test).

observed for NOX2 (Fig. 6A). Oxidative damage to cellular components was assessed by western blot measuring adducts of 4-hydroxynonenal (4-HNE), a product of lipid oxidation, with liver proteins. 4-HNE-protein adduct levels were similar among groups (Fig. 6B), confirming an initial stage in NAFLD development as a consequence of 8 weeks HFD consumption.

\section{Discussion}

The present work demonstrated that a short-term supplementation with cyanidin and delphinidin could prevent and/or reverse HFD-induced endotoxemia and the associated liver inflammation in mice. These results agree with previous evidence indicating that $\mathrm{AC}$ consumption is linked to an improvement of diseases having an important inflammatory component. In this regard, dietary intake of AC and/or berries as source of ACs were found to be associated to a lower risk of type 2-diabetes, ${ }^{10}$ cardiovascular disease ${ }^{11}$ and all-cause mortality. ${ }^{29}$ In terms of liver inflammation, studies in cells and animals are supportive of a protective effect, while evidence in humans is still scarce. ${ }^{30}$ Our previous study showed that supplementation for 14 weeks with the CDRE, inhibits HFDinduced steatosis, liver inflammation, insulin resistance and 

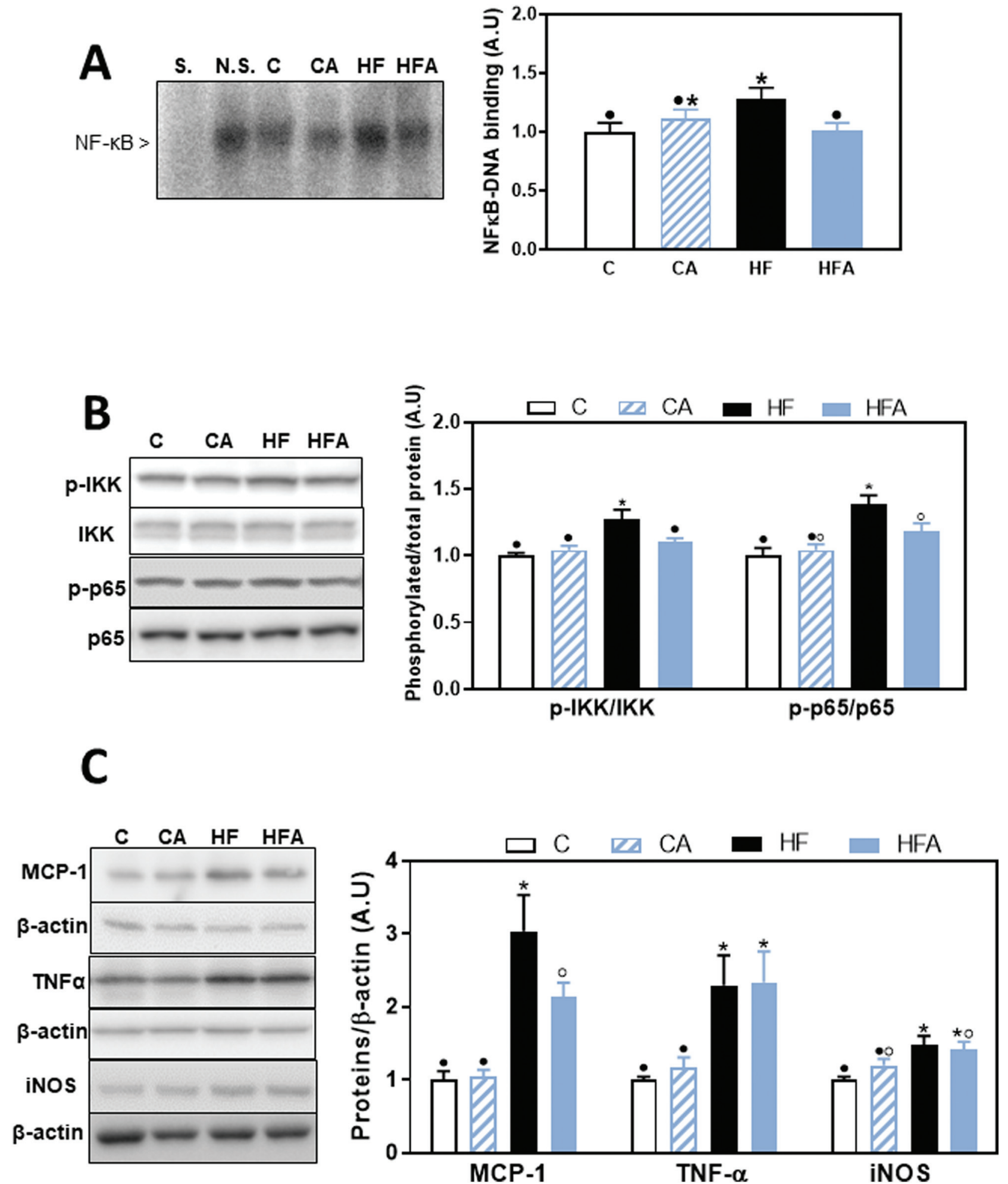

Fig. 4 Effects of supplementation with cyanidin and delphinidin on NF- $\mathrm{KB}$ activation and downstream expression of proteins involved in inflammation in mice fed a HFD. Mice were fed the different diets as described in methods. After 8 weeks on the corresponding diets the following parameters were measured in liver: A - NF-kB-DNA binding in liver nuclear fractions measured by EMSA. Representative EMSA images are shown on the left panel. To assess the specific bands, a control nuclear fraction was incubated in the presence of a 100-fold molar excess of unlabeled oligonucleotide containing the consensus sequence for a non-specific (N.S.) (FOXO-1) or specific (S.) (NF- $\mathrm{kB}$ ) transcription factor before the binding assay. B - NF-KB activation and C - downstream protein expression were measured by western blot: B - phosphorylation of IKK (Ser176/180) and p65 (Ser536), C - MCP-1, TNF $\alpha$, and iNOS. Bands were quantified and values referred to total protein levels ( $p 65$, IKK) or $\beta$-actin levels (loading control for MCP-1, TNF $\alpha$, and iNOS). All results for CA, HF and HFA were referred to control group values (C). Results are shown as mean \pm SE of 9-10 mice per group. Values having different symbols are significantly different $(P<0.05$, one-way ANOVA test). 

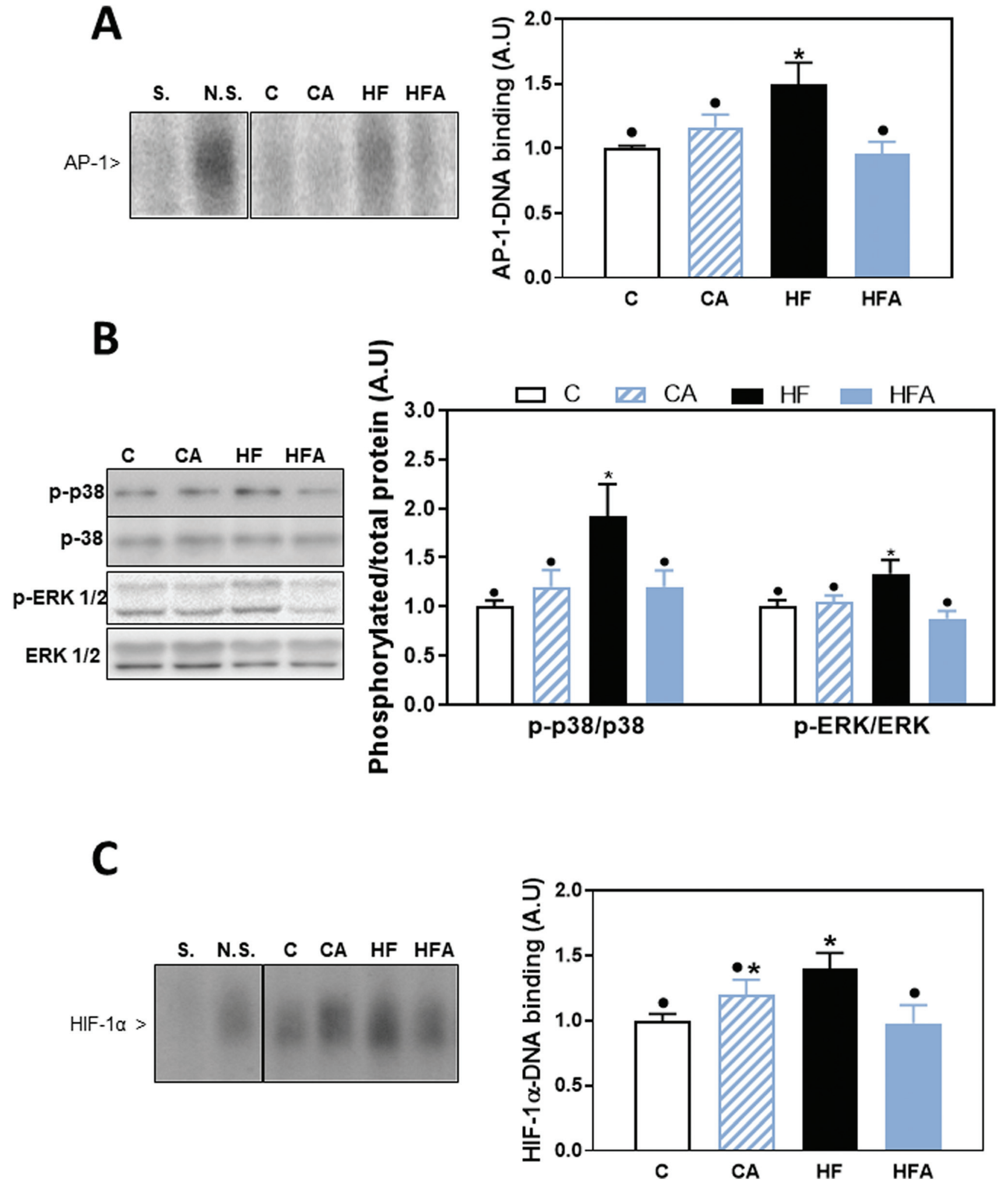

Fig. 5 Effects of supplementation with cyanidin- and delphinidin on AP-1, MAPK and HIF activation in mice fed a HFD. Mice were fed the different diets as described in methods. After 8 weeks on the corresponding diets the following parameters were measured in liver: A - AP-1-DNA binding and C - HIF-1-DNA binding in liver nuclear fractions were measured by EMSA. Representative EMSA images are shown on the left panels. To assess the specific bands, a control nuclear fraction was incubated in the presence of a 100 -fold molar excess of unlabeled oligonucleotide containing the consensus sequence for a non-specific (N.S.) (FOXO-1) or specific (S.) (AP-1 or HIF-1) transcription factor before the binding assay. B - MAPK activation was evaluated measuring by western blot the phosphorylation of p38 at Thr180/Tyr182, and ERK1/2 at Thr202/Tyr204. Bands were quantified and values referred to total protein levels (p38, ERK1/2). All results for CA, HF and HFA were referred to control group values (C). Results are shown as mean \pm SE of 9-10 mice per group. Values having different symbols are significantly different $(P<0.05$, one-way ANOVA test). 
A
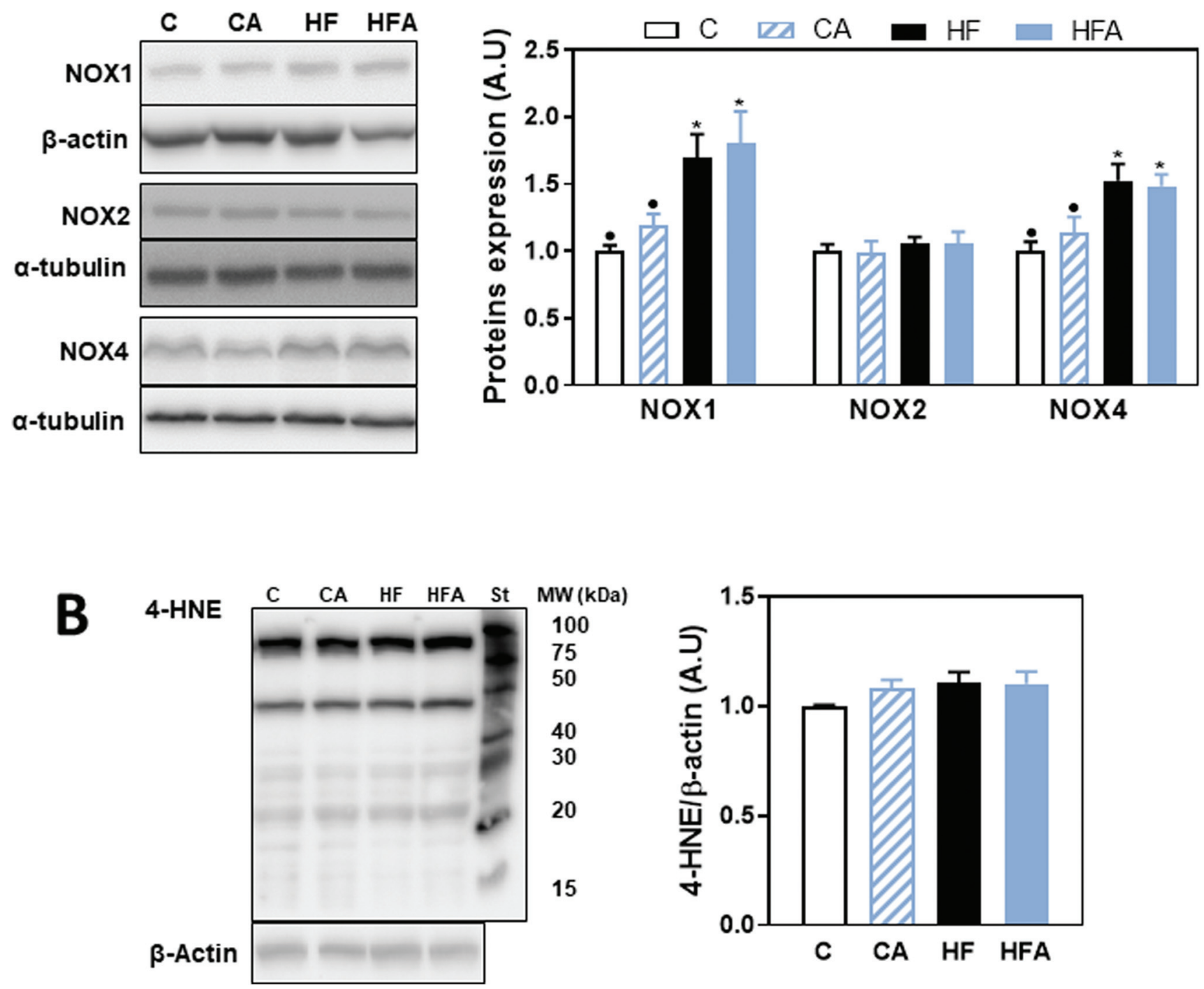

Fig. 6 Effects of supplementation with cyanidin and delphinidin on parameters of liver oxidative stress in mice fed a HFD. Mice were fed the different diets as described in methods. After 8 weeks on the corresponding diets the following parameters were measured in liver by western blot: A - NOX1, gp91phox (NOX2) and NOX4 and B - HNE-protein adducts. Bands were quantified and values referred to $\beta$-actin or $\alpha$-tubulin levels (loading controls). St: molecular weight standard (MW). Results for CA, HF and HFA were referred to control group values (C). Results are shown as mean \pm SE of 9-10 mice per group. Values having different symbols are significantly different $(P<0.05$, one-way ANOVA test).

oxidative stress in mice. ${ }^{17}$ The current study was aimed to investigate if dietary supplementation of mice for 4 weeks with CDRE could revert or mitigate an established liver pro-inflammatory condition caused by 4 weeks consumption of a HFD. Overall, CDRE supplementation did not revert or prevent HFDinduced adiposity, steatosis and high circulating levels of triglycerides, cholesterol, glucose and insulin, but normalized metabolic endotoxemia and mitigated liver inflammation.

We observed that metabolic endotoxemia was already increased in mice after consumption of the HFD for 4 weeks, remaining elevated after 8 weeks on the diet. Supplementation with CDRE restored LPS plasma levels to control values. This normalization of plasma LPS by CDRE suggests that the endotoxemia associated to Western style diets and/or obesity could be mitigated by dietary changes that include AC-rich fruits and vegetables and/or AC supplementation. At a molecular level, the cyanidin- and delphinidin-rich blend could mitigate endotoxemia by promoting healthier microbiota profiles and decreasing LPS paracellular transport caused by loss of intestinal barrier function ${ }^{31}$ or LPS transcellular co-transport with absorbed lipids. ${ }^{5,6}$ However, current data do not allow to identify the involved mechanisms. The beneficial effects of AC reverting endotoxemia are relevant to the liver, given that LPS triggers liver inflammation, which in conjunction with steato- 
sis, can evolve into NAFLD and subsequently non-alcoholic steatohepatitis (NASH). ${ }^{32-34}$

The inflammatory condition associated with endotoxemia, is reflected in the high liver levels of TLR2 and TLR4 after 8 weeks on the HFD diet. The absence of high TLR4 levels at 4 weeks can be due to the fact that the liver maintains low levels of TLR4 expression and can manage LPS without significant inflammation. ${ }^{9}$ However, as we observed after 8 weeks, sustained exposure to high LPS levels leads to TLR4 upregulation. TLR2 expression was also upregulated by 8 weeks HFD consumption, which was prevented by CDRE supplementation. The relationship between these two receptors and LPS is complex; while LPS is not a TLR2 ligand, TLR2 is required for LPS-induced TLR4 activation in kidney. ${ }^{35}$ Thus, the prevention of HFD-induced overexpression of both TLR2 and TLR4 appears to be central in the capacity of cyaniding and delphinidin to mitigate liver inflammation.

In accordance with previous results, the HFD was associated with the upregulation of proinflammatory and profibrotic cascades downstream TLR2 and TLR4, i.e. NF-kB, p38, ERK1/2, AP-1 and HIF-1. ${ }^{28}$ These signaling pathways cross talk in ways that can escalate inflammation. ${ }^{36,37}$ Supplementation with the CDRE fully prevented or reverted the activation of these cascades. In terms of the expression of molecules resulting from the inflammatory process and the associated oxidative stress, 8 weeks consumption of the HFD led to increased levels of MCP-1, TNF $\alpha$, iNOS, and the NADPH oxidases NOX1 and NOX4. While supplementation with CDRE mitigated MCP-1 increase, it did not improve any of the other parameters. This discrepancy can be in part explained by the different timing of protein expression during the inflammatory process and/or different signaling regulation of each of these proteins. In addition, different cell types are involved in liver inflammation, which can also explain the observed different responses to cyaniding and delphinidin supplementation. Kupffer cells seem to be relevant in the hepatic inflammatory response to LPS, because they are responsible for the clearing of LPS arriving to the liver through the portal vein and for the initiation of TLR4-mediated inflammation. ${ }^{38}$ In fact, Kupffer cell depletion inhibits the recruitment of bone marrow macrophages and mitigates steatohepatitis. ${ }^{39}$ Thus, the observed decrease in MCP-1 expression upon 4-week CDRE supplementation of HFD-fed mice may be highly relevant in reducing the recruitment of macrophages and the amplification of hepatic inflammation.

\section{Conclusions}

Prevention of endotoxemia and downregulation of liver TLR2 and TLR4 can in part explain the capacity of AC, especially cyanidin and delphinidin, to prevent the activation of proinflammatory signals that are involved in the development of liver inflammatory diseases, e.g. NAFLD. A limitation of this study is the use of a complex mixture that does not allow identifying precisely the molecules responsible for the observed effects.
On the other hand, our previous studies using isolated AC pointed to cyanidin and delphinidin as the particular AC involved in providing anti-inflammatory protection. ${ }^{15,31}$ Until having a definitive response, results support the concept that increasing the consumption of fruits and vegetables, especially those rich in cyanidin and delphinidin, could protect from the adverse consequences of unhealthy diets on liver functionality. While not all the adverse consequences of HFD consumption were reverted by the CDRE, a longer period of AC supplementation could have additional beneficial actions.

\section{Author contributions}

E. C. and D. E. I. ran all the experiments. K. E. M. scored the histology pictures. P. I. O. designed the study. P. I. O., C. G. F., E. C. and D. E. I. wrote the manuscript. All authors revised the article, critically reviewed it for intellectual content, and approved the final version.

\section{Conflicts of interest}

S. M. W., S. N. H. and M. B. are employed by Pharmanex Research, NSE Products Inc., Provo, UT, USA, the company that provided the test mix and research funding. C. G. F. and P. I. O. have received research grants from NSE Products Inc. C. G. F. and P. I. O. are members of the NSE Products Inc. Scientific Advisory Board. C. G. F. and P. I. O. have received research grants from other food companies and government agencies with an interest in health and nutrition.

\section{Acknowledgements}

Funding was provided by a research grant from Pharmanex Research, NSE Products Inc., Provo, UT, USA. PIO is correspondent researcher from CONICET, Argentina. Study design and graphical abstract were generated with BioRender.com.

\section{References}

1 P. D. Cani, M. Osto, L. Geurts and A. Everard, Involvement of gut microbiota in the development of low-grade inflammation and type 2 diabetes associated with obesity, Gut Microbes, 2012, 3, 279-288.

2 E. Patterson, P. M. Ryan, J. F. Cryan, T. G. Dinan, R. P. Ross, G. F. Fitzgerald and C. Stanton, Gut microbiota, obesity and diabetes, Postgrad. Med. J., 2016, 92, 286-300.

3 A. P. Moreira, T. F. Texeira, A. B. Ferreira, M. C. Peluzio and R. C. Alfenas, Influence of a high-fat diet on gut microbiota, intestinal permeability and metabolic endotoxaemia, Br. J. Nutr., 2012, 108, 801-809.

4 F. Laugerette, C. Vors, A. Géloën, M. A. Chauvin, C. Soulage, S. Lambert-Porcheron, N. Peretti, M. Alligier, R. Burcelin, M. Laville, H. Vidal and M. C. Michalski, 
Emulsified lipids increase endotoxemia: possible role in early postprandial low-grade inflammation, $J$. Nutr. Biochem., 2011, 22, 53-59.

5 S. Ghoshal, J. Witta, J. Zhong, W. de Villiers and E. Eckhardt, Chylomicrons promote intestinal absorption of lipopolysaccharides, J. Lipid Res., 2009, 50, 90-97.

6 C. Vors, G. Pineau, J. Drai, E. Meugnier, S. Pesenti, M. Laville, F. Laugerette, C. Malpuech-Brugère, H. Vidal and M.-C. Michalski, Postprandial endotoxemia linked with chylomicrons and lipopolysaccharides handling in obese versus lean men: a lipid dose effect trial, J. Clin. Endocrinol. Metab., 2015, 100, 3427-3435.

7 P. D. Cani, R. Bibiloni, C. Knauf, A. Waget, A. M. Neyrinck, N. M. Delzenne and R. Burcelin, Changes in gut microbiota control metabolic endotoxemia-induced inflammation in high-fat diet-induced obesity and diabetes in mice, Diabetes, 2008, 57, 1470-1481.

8 J. B. Soares, P. Pimentel-Nunes, R. Roncon-Albuquerque and A. Leite-Moreira, The role of lipopolysaccharide/tolllike receptor 4 signaling in chronic liver diseases, Hepatol. Int., 2010, 4, 659-672.

9 N. Nakamoto and T. Kanai, Role of toll-like receptors in immune activation and tolerance in the liver, Front. Immunol., 2014, 5, 221.

10 X. Guo, B. Yang, J. Tan, J. Jiang and D. Li, Associations of dietary intakes of anthocyanins and berry fruits with risk of type 2 diabetes mellitus: a systematic review and meta-analysis of prospective cohort studies, Eur. J. Clin. Nutr., 2016, 70, 1360-1367.

11 A. Cassidy, Berry anthocyanin intake and cardiovascular health, Mol. Aspects Med., 2017, 61, 76-82.

12 K. Riazi, M. Raman, L. Taylor, M. G. Swain and A. A. Shaheen, Dietary patterns and components in nonalcoholic fatty liver disease (NAFLD): what key messages can health care providers offer?, Nutrients, 2019, 11, 2878.

13 P. I. Oteiza, C. G. Fraga, D. A. Mills and D. H. Taft, Flavonoids and the gastrointestinal tract: Local and systemic effects, Mol. Aspects Med., 2018, 61, 41-49.

14 P. I. Oteiza, C. G. Fraga and M. Galleano, Linking biomarkers of oxidative stress and disease with flavonoid consumption: From experimental models to humans, Redox Biol., 2021, 42, 101914.

15 E. Cremonini, A. Mastaloudis, S. N. Hester, S. V. Verstraeten, M. Anderson, S. M. Wood, A. L. Waterhouse, C. G. Fraga and P. I. Oteiza, Anthocyanins inhibit tumor necrosis alpha-induced loss of Caco-2 cell barrier integrity, Food Funct., 2017, 8, 29152923.

16 E. Cremonini, E. Daveri, A. Mastaloudis and P. I. Oteiza, (-)-Epicatechin and anthocyanins modulate GLP-1 metabolism: evidence from C57BL/6J mice and GLUTag cells, J. Nutr., 2021, 151, 1497-1506.

17 E. Daveri, E. Cremonini, A. Mastaloudis, S. N. Hester, S. M. Wood, A. L. Waterhouse, M. Anderson, C. G. Fraga and P. I. Oteiza, Cyanidin and delphinidin modulate inflammation and altered redox signaling improving insulin resistance in high fat-fed mice, Redox Biol., 2018, 18, 16-24.

18 S. Reagan-Shaw, M. Nihal and N. Ahmad, Dose translation from animal to human studies revisited, FASEB J., 2008, 22, 659-661.

19 Phenol Explorer, http://phenol-explorer.eu/contents/food/ 77, (accessed November 2021).

20 T. E. Weber, S. L. Trabue, C. J. Ziemer and B. J. Kerr, Evaluation of elevated dietary corn fiber from corn germ meal in growing female pigs, J. Anim. Sci., 2010, 88, 192201.

21 A. Sündermann, L. F. Eggers and D. Schwudke, in Encyclopedia of Lipidomics, Springer, Netherlands, Dordrecht, ed. M. R. Wenk, 2016.

22 D. E. Kleiner, E. M. Brunt, M. Van Natta, C. Behling, M. J. Contos, O. W. Cummings, L. D. Ferrell, Y. C. Liu, M. S. Torbenson, A. Unalp-Arida, M. Yeh, A. J. McCullough and A. J. Sanyal, Nonalcoholic Steatohepatitis Clinical Research, Design and validation of a histological scoring system for nonalcoholic fatty liver disease, Hepatology, 2005, 41, 1313-1321.

23 A. Bettaieb, M. A. Vazquez-Prieto, C. R. Lanzi, R. M. Miatello, F. G. Haj, C. G. Fraga and P. I. Oteiza, (-)-Epicatechin mitigates high fructose-associated insulin resistance by modulating redox signaling and endoplasmic reticulum stress, Free Radicals Biol. Med., 2014, 72, 247-256.

24 G. G. Mackenzie, F. Carrasquedo, J. M. Delfino, C. L. Keen, C. G. Fraga and P. I. Oteiza, Epicatechin, catechin, and dimeric procyanidins inhibit PMA-induced NF-kappaB activation at multiple steps in Jurkat T cells, FASEB J., 2004, 18, 167-169.

25 T. C. Contreras, E. Ricciardi, E. Cremonini and P. I. Oteiza, (-)-Epicatechin in the prevention of tumor necrosis alphainduced loss of Caco-2 cell barrier integrity, $A B B, 2015, \mathbf{5 7 3}$, 84-91.

26 S. Caldwell, Y. Ikura, D. Dias, K. Isomoto, A. Yabu, C. Moskaluk, P. Pramoonjago, W. Simmons, H. Scruggs, N. Rosenbaum, T. Wilkinson, P. Toms, C. K. Argo, A. M. AlOsaimi and J. A. Redick, Hepatocellular ballooning in NASH, J. Hepatol., 2010, 53, 719-723.

27 S. Tandra, M. M. Yeh, E. M. Brunt, R. Vuppalanchi, O. W. Cummings, A. Ünalp-Arida, L. A. Wilson and N. Chalasani, Presence and significance of microvesicular steatosis in nonalcoholic fatty liver disease, J. Hepatol., 2011, 55, 654-659.

28 S. E. Corcoran and L. A. O'Neill, HIF1 $\alpha$ and metabolic reprogramming in inflammation, J. Clin. Invest., 2016, 126, 3699-3707.

29 K. L. Ivey, M. K. Jensen, J. M. Hodgson, A. H. Eliassen, A. Cassidy and E. B. Rimm, Association of flavonoid-rich foods and flavonoids with risk of all-cause mortality, Br. J. Nutr., 2017, 117, 1470-1477.

30 L. Valenti, P. Riso, A. Mazzocchi, M. Porrini, S. Fargion and C. Agostoni, Dietary anthocyanins as nutritional therapy for nonalcoholic fatty liver disease, Oxid. Med. Cell. Longevity, 2013, 2013, 145421. 
31 E. Cremonini, E. Daveri, A. Mastaloudis, A. M. Adamo, D. Mills, K. Kalanetra, S. N. Hester, S. M. Wood, C. G. Fraga and P. I. Oteiza, Anthocyanins protect the gastrointestinal tract from high fat diet-induced alterations in redox signaling, barrier integrity and dysbiosis, Redox Biol., 2019, 26, 101269.

32 G. Carpino, M. Del Ben, D. Pastori, R. Carnevale, F. Baratta, D. Overi, H. Francis, V. Cardinale, P. Onori, S. Safarikia, V. Cammisotto, D. Alvaro, G. Svegliati-Baroni, F. Angelico, E. Gaudio and F. Violi, Increased liver localization of lipopolysaccharides in human and experimental NAFLD, Hepatology, 2020, 72, 470-485.

33 D. Ferro, F. Baratta, D. Pastori, N. Cocomello, A. Colantoni, F. Angelico and M. Del Ben, New insights into the pathogenesis of non-alcoholic fatty liver disease: gut-derived lipopolysaccharides and oxidative stress, Nutrients, 2020, 12, 2762.

34 V. Männistö, M. Färkkilä, P. Pussinen, A. Jula, S. Männistö, A. Lundqvist, L. Valsta, V. Salomaa, M. Perola and F. Åberg, Serum lipopolysaccharides predict advanced liver disease in the general population, JHEP Rep., 2019, 1, 345-352.
35 D. W. Good, T. George and B. A. Watts 3rd, Toll-like receptor 2 is required for LPS-induced Toll-like receptor 4 signaling and inhibition of ion transport in renal thick ascending limb, J. Biol. Chem., 2012, 287, 20208-20220.

36 M. G. Dorrington and I. D. C. Fraser, NF-кB Signaling in macrophages: dynamics, crosstalk, and signal integration, Front. Immunol., 2019, 10, 705.

37 L. D'Ignazio, D. Bandarra and S. Rocha, NF-кB and HIF crosstalk in immune responses, FEBS J., 2016, 283, 413424.

38 C. A. Rivera, P. Adegboyega, N. van Rooijen, A. Tagalicud, M. Allman and M. Wallace, Toll-like receptor-4 signaling and Kupffer cells play pivotal roles in the pathogenesis of non-alcoholic steatohepatitis, J. Hepatol., 2007, 47, 571579.

39 K. Miura, L. Yang, N. van Rooijen, H. Ohnishi and E. Seki, Hepatic recruitment of macrophages promotes nonalcoholic steatohepatitis through CCR2, Am. J. Physiol.: Gastrointest. Liver Physiol., 2012, 302, G1310-G1321. 